\title{
Use of Web-assisted and Corpus-based Technology in College English Writing Course
}

\author{
The Use of Pigai.org in Xiamen University
}

\author{
Huang Lingyi \\ College of Foreign Languages and Cultures \\ Xiamen University \\ Xiamen, China \\ ilovexmu2015@126.com
}

\begin{abstract}
The newly developed technology_pigai.org is an effective system in helping teachers mark articles and providing revision feedbacks instantly. The introduction of the system into Xiamen University proved to be a win-win model, and was accepted by both teachers and students. As can be seen from the recently-held national writing contest 2015 and the survey conducted in May, this new technology gives teachers new options in doing the writing tasks and brings incentives to students to revise their composition and improve the score. Although like most new techniques, this system faces question in handling the key element in writing - critical thinking, it does promise a bright prospect of a more flexible and interesting writing experience.
\end{abstract}

Keywords-pigai.org; Writing Course; Revision; Webassisted; corpurs

Recent years have seen fast development of China's Higher Education, and the university admission rate has also risen from $69 \%$ in 2010 to $74.3 \%$ in 2015 [1]. The most direct impact on the educational system is the everlarger expansion of class-size. For college English Course, the average class size in most universities is over 40, even 50. As a key university, Xiamen University faces similar pressure in balancing a good teaching quality and a rational student-teacher ratio.

Among the different teaching tasks, writing course is the most demanding and needs much cooperation between the teachers and students. In-class teaching and after-class practices play equally important role in the learning process. However, the diverse levels of English proficiency of students do not get narrowed down even with a large amount of attention paid and devotion made, and confronted with greater difficulties in such a large class. Yet students, facing increasing fierce competitions from the job market, have higher expectation for an effective writing course.

A recently-introduced technology - a website that is Web-assisted and Corpus-based has been put into official use in Xiamen University and begun to see progress in assisting the teaching and learning process. How effective are the functions and how does it meet the requirement of both teachers and students? Would it replace the teachers' role altogether? What are the prospects of such a new technology in universities?

\section{THE COLLEGE ENGLISH WRITING COURSE}

Despite the fierce requirement from the job market, the urgent demand of an effective writing course does not meet with sufficient welcome and enthusiasm from the teachers. Under the soaring pressure from the managing organs of most universities to restructure the credit system, the overall credit of college English course has been greatly reduced. Therefore, in view of the limited time allocation, the important part of a writing course -in-class writing practices would not be a plausible option.

Moreover, most undergraduate students do not get enough training in high school and, more or less, are restrained by the coping tactics taught by their middle school teachers to deal with national entrance examination. So besides basic writing skills, the focus in class would be on thought-provoking and critical-thinking. And these further leave little time for basic language training, which most students did not get satisfactorily trained in high school. But we cannot deny these basic writing skills are important and fundamental, and when compositions are written, they need detailed correction and comments.

However, we must admit that a lot of teachers either lack enough time and energy to mark and revise piles of writing articles, or even lack enthusiasm to tackle such a tedious task. And the training of a qualified writing course teacher is not easy in itself.

In a word, the current demand of a good and efficient writing course does not meet with enough enthusiasm and have effective experiments.

\section{THE USE OF THE WEB-ASSISTED AND CORPUS - BASED TECHNOLOGY IN WRTING COURSE}

\section{A. The New Technolgoy-pigai.org}

Recently a new website powered by Beijing Ciku Company has been widely used by many universes in China as an important means to ease the burden of correcting compositions in English writing course (in the past, schools like Guzhou University had made similar tries and claimed that they applied the theory of Krashen [2] into their writing and speaking course [3]). This new technology is web-assisted and corpus-based, and provides instant marking and feedbacks to every submission of articles. Students can submit articles anytime and anywhere via internet. The most striking feature is that it gives students feedbacks sentence by sentence and allows revision limitless times. The comments are detailed, immediate, which can be divided into grammar mistakes, collocation problems, spelling, cohesive problems, etc. Some mistakes are pointed out with correct versions given 
below. Some, given hints for further improvement, can be checked with the corpus-based dictionary at the bottom of the revision page. Students' works are marked according to different standards set by the teachers (like CET 4, CET 6, TOFEL, etc), providing flexible choices to meet different requirements.

The important feature of Human-Computer Interaction Techniques remarkably challenges the traditional way, which students have to wait for a certain period of time before they get their marked paper back and depend largely on teachers' proficiency and efficiency. The human marking has no fixed standard. No explanation for errors would also involve problems of lacking further mutual interaction. In view of the large discrepancy in the studentteacher ratio, a student cannot get enough feedback for every article he submits. In this aspect, this new technology gives equal treatment to every student, and would never feel exhausted for every new article submitted. The interaction is fast, detailed and without emotional pressure.

\section{B. A Win-win New Teaching Model}

The use of this new technology in writing course also brings forward a new teaching model -web-assisted and corpus-based, which may be the new trend of the new digital age, in which the teaching model must be propelled by the internet technology [4].

First, teacher can assign tasks online and giving topics either from personal collections, or directly from the paper database provided by the website or topics shared by other teachers using this technology all over the country. This provides new bank for practice topics and ensures new and latest resources shared timely. Then when most of the

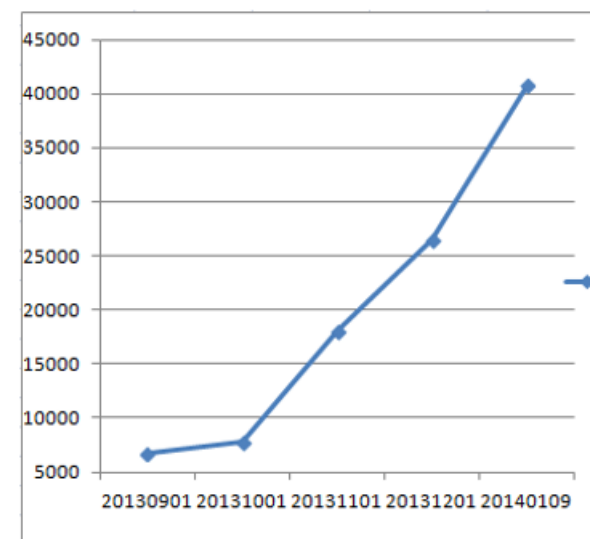

Figure 1. Articles Submitted by Students (2013.9-2014.1)

From the above figures, we can clearly see that the new technology was accepted by both sides in the first experimental stage. The number of articles submitted and wiring tasks assigned was on the increase month after month. Nearly all the college English teachers in Xiamen University learned to use the system and got positive feedbacks from students. After that, the system was purchased and put into full use.

\section{NATIONAL WRITING COMPETITION IN 2015}

After the trial use for one year and the system officially launched, both teachers and students reveal positive feedbacks. And in April 2015, all the undergraduate simple language mistakes are corrected by the system, teachers could focus more on the structure and cohesive devices, and emphasize more on critical thinking in writing process. Attention and energy are diverted to the most important part of the practice, so teachers can save the trouble and hit the nail on the head when they do the marking in the second stage.

On the other hand, the students can submit articles and revise them endless times before the deadline. A track will be recorded and can be shown both to teachers and students. For revision feedbacks are given right after the submission and scores get changed every time when they make progress, students usually get the incentive to revise and improve, hoping to get a better result next time. In this stage, students take the initiative in the writing process.

Another important feature I would strongly point out is that the technology can effectively prevent plagiarism by using the corpus technique. Those who plagiarize would be checked out by the system based on the corpus, even giving out the source sentence by sentence. It also gives alarms to teachers automatically. This function greatly reduces the risk of academic cheating and gives enough deterrence to students.

\section{Priliminary Experiment of The New System}

The new technology was tried at writing course in Xiamen University from September 2013. After one term, we collected the basic usage information and found that this new system was warmly welcomed and effectively used by most teachers and students. From September 1st, 2013 to January 9th, 2014, 65 teachers and 9518 students registered on the website. During the term, students submitted 40,739 articles. [5]

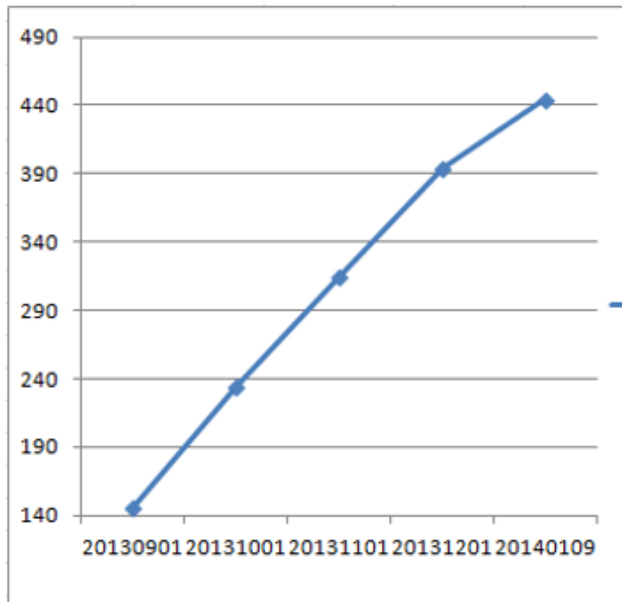

Figure 2. Writing Tasks Assigned by Teachers (2013.9-2014.1)

students that take English courses took part in a national wide writing competition, using the pigai system. This competition lasted from April 16th to May 31st; teachers from 2,792 schools (including universities and high schools) in 31 provinces took part in this contest. 1,093,126 compositions had been submitted [6], which may be the first time in history.

During the contest, teachers allowed students to revise their articles before the deadline, so most students (over $71 \%$ ) made revisions. (Detailed statistics can be seen below in Fig.3). The average revision times is 7.1007. And the total number of errors corrected is $4,167,188[7]$. 


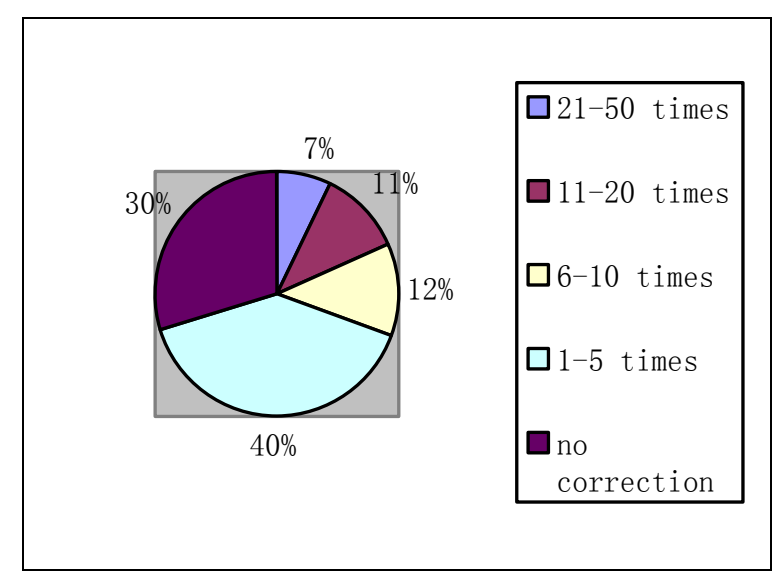

Figure 3. Revision Times of Each Article

And from the contrast between the initial version and final version of the composition, we can see that students from different level of universities all saw improvement of the scores (at least 3-4 points). And students from key universities (the universities under the 985 Plan) improve

And also from the human-machine interactive revision process, the errors in the final version drop at least $30 \%$ $50 \%$. Especially for grammatical mistakes, they decrease by $42.77 \%$; spelling mistakes, drop by $15.28 \%$ [9].

From the above statistics, we can see that the system has successfully deal with the basic writing problems, like grammatical mistakes, spelling errors and pushed most users to make revision after initial submission. It has formed a new habit into the students to revise articles and make self-checking. It also gives students an instant help when all the ideas are fresh.

\section{SURVEY IN 2015}

After the official launch of the system and 3 years' intense use, a survey focusing on the satisfactory level of students toward the current teaching model was conducted from May 20th to 31st, 2015 among the first and second year undergraduates in Xiamen University. 2,237 students took part in the survey which was done online on website www.sojump.com. [10]

When asked about the time allocated to in-class teaching, $73.94 \%$ of the students consider $2+2$ teaching

New technology always plays the role of a double sword, when more teaching and practices are conducted on website, what's the role of teachers? Will students all benefit from the new technology and how about those who find it hard to write and think before the screen? Can we trust the technology as effective and flexible as human teachers?

All these questions lead to the weakness part of the system. We must admit that no matter how advanced the technology develops, the role of human teachers are irreplaceable. Technology can only help us find out lexical mistakes and give suggestions on word choices or sentence structures. The critical thinking - the key and core part of a good writing can never be fully understood and taught by machines. All these must and can only be done by humans.

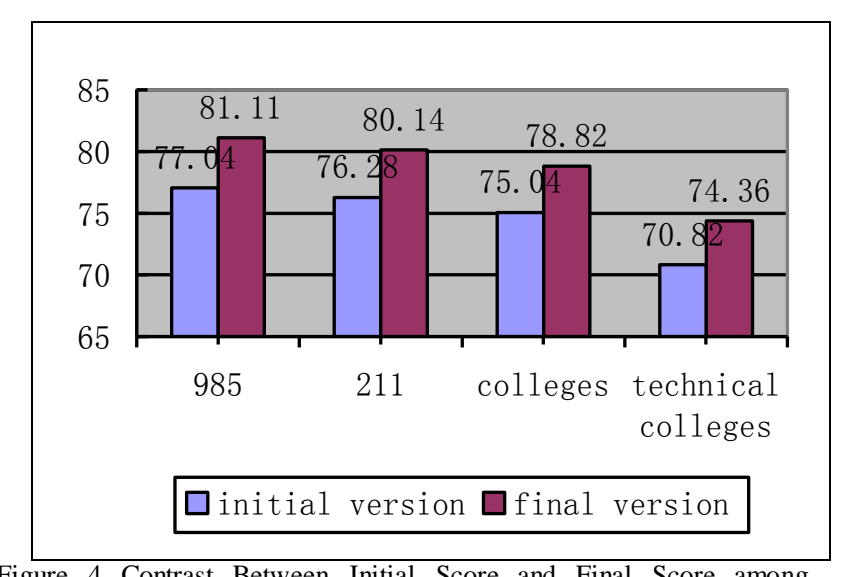

Figure 4 Contrast Between Initial Score and Final Score among Different Universities

most (4.07 points) [8]. That shows a positive improvement in students' writing performance in using the system. model ( 2 hour in-class teaching time +2 hour self-learning time) satisfactory and agreed that 2-hour a week in-class lecturing as the proper choice [11]. Therefore, we can see that the current restructuring of the credit system has given students more say in the teaching process. We cannot expect to have more in-class time to practice writing, which either is out of line with the present trend or lack possible human resources to tackle it. So this new technology gives teachers new options and possibilities to conduct out-of-class practices.

When asked about the use of pigai.org in their writing process, $73.18 \%$ of the students felt satisfied and only $26.80 \%$ expressed their dissatisfaction [12]. From the contrast of the number, it is obvious that this technology has begun to gain popularity among young students and do give them enough help and incentives in the learning process. The acceptance by the students is the key to the success of this new technology, for it is the users that can tell effectiveness of the system.

\section{PROBLEMS AND CHALLENGES}

And technology also reduces the communication time teacher and students spent. This was also echoed in a survey done in July 2013 among 218 undergraduate students in Xiamen University [13]. $45.8 \%$ of the students said they find it hard to adjust to doing exercises on computer, $47.24 \%$ said that they do not have sufficient time to communicate with teachers, and $29.83 \%$ said the technical clichés annoy them sometimes. This is a reflection of a common problem posed at the era of the computers - how can we balance the time spent before screens and those in face-to -face communication.

Teachers should never take for granted that this technology will automatically take away all the work in the 
writing course. It is just a basic tool that helps to relieve the burden of some easy, simple and tedious work. Teachers should interfere in the latter stage and give suggestions on the overall idea and structure. This imposes higher requirement not only on teachers' teaching skills, but also their way of thinking and knowledge storing. When students ask questions, teachers should be able to grasp the core and in-depth problems and point out the common mistakes that would be avoidable in future practice.

\section{CONCLUSIONS}

The development of the new technology-pigai.org gives a new opportunity for the improvement of the writing course in College English. It greatly relieves the burden of the teachers and allows them to focus on the important and key part of writing ---critical thinking. This proves to get positive results from the survey of students.

On the other hand, students get immediate feedback and detailed instruction for every article they submit. They have more incentives to revise and have made progress in the revision process. When in-class instruction time is limited and teacher-student ratio is not satisfactory, this new system give us a new option that encourage student to have more initiative in their study and practice the model of tech-assisted learning. Although the technology helps a lot in basic language checking, the role of the teachers would not be replaced after all.

\section{ACKNOWLEDGMENTS}

This work is supported by the Fundamental Research Grant for the Central Universities of China, at the Xiamen University, Xiamen, China. The Grant No is 0650-ZK1055.

\section{REFERENCES}

[1] The Statistics of Entrance Examination Admission Rate (19772014), Sina Education, http://edu.sina.com.cn/gaokao/2015-0618/1435473862.shtml, accessed on Dec.10,2015.

[2] S.D. Krashen, Principles and Practice in Second Language Acquisition, Oxford: Pefamon, 1982,p9-32.

[3] Paul Shoebottom, “An Introduction to The Work of Stephen Krashen", October http://esl.fis.edu.teachers/support/krashen.htm, July2013.

[4] Schunk. D. H. "Learning Theories: An Educational Perspective". Nanjing: Jiangsu Education press.2000.

[5] Report on The Use of Pigai.org in Xiamen University(2013.92014.1), www.pigai.org ,2014.

[6] Report on English Writing Contest 2015-Millions of Particapants Writing the Same Topic,www.pigai.org, 2015.

[7] Survey on 2+2 College English Course 2015, www.sojump.com, May 2015.

[[8] Survey on College English Course 2013 in Xiamen University, a) www.sojump.com, July 2013. 